\title{
ARTÍCULO 20
}

"Intercambio de información

1. Las Autoridades Competentes de los Estados Parte se comunicarán la información relacionada con:

a) las medidas adoptadas para la aplicación del presente Convenio, y

b) las modificaciones de sus respectivas legislaciones que puedan afectar a la aplicación del presente Convenio.

2. A efectos de la aplicación del presente Convenio, las Autoridades e Instituciones Competentes de los Estados Parte se prestarán sus buenos oficios y actuarán como si se tratase de aplicar sus propias legislaciones. La asistencia administrativa facilitada por dichas autoridades e instituciones será, por regla general, gratuita.

3. Las Instituciones Competentes, conforme el principio de buena administración, responderán a todas las peticiones en un plazo razonable y, a tal efecto, comunicarán a las personas interesadas cualquier información necesaria para hacer valer los derechos que les otorga el presente Convenio.

4. De igual modo, las personas interesadas quedan obligadas a informar cuanto antes a las instituciones del Estado Parte competente y del Estado Parte de residencia, de cualquier cambio en su situación personal o familiar que tenga incidencia en su derecho a las prestaciones establecidas en el presente Convenio".

\section{FRANCISCO MIGUEL ORTIZ GONZÁLEZ CONDE}

Doctorando. Departamento de Derecho del Trabajo y Seguridad Social

Universidad de Murcia 


\section{RESUMEN}

El artículo 20 del Convenio Multilateral Iberoamericano de Seguridad Social tiene especial relevancia porque sin intercambio de información no se podría dar cumplimiento a los principios inspiradores del Convenio

PALABRAS CLAVE: Autoridades competentes, instituciones competentes, información, Convenio Multilateral Iberoamericano de Seguridad.

\section{ABSTRACT}

Article 20 of the Iberoamerican Multilateral Agreement on Social Security is of particular relevance because without exchange of information the principles underlying the Convention Without could not be fulfilled

KEYWORDS: Competent authorities, competent institutions, Iberoamerecan Multilateral Agreement. 
SUMARIO

I. INTRODUCCIÓN

II. EL INTERCAMBIO DE INFORMACIÓN

III. MEDIDAS SIMILARES REGULADAS EN OTROS CONVENIOS BILATERALES

IV. CONCUSIONES 


\section{INTRODUCCIÓN}

Suele atribuirse a Francis Bacon la autoría de la famosa cita "la información es poder". Si bien, este artículo no podrá confirmar dicho extremo, si se puede utilizar esta frase como punto de inicio al comentario ahora propuesto.

Tomando la cautela de revisar y actualizar la cita, se puede decir que la información en sí no es poder, sino la administración y la coordinación razonable de la información ${ }^{1}$, y aquí es donde radica la grandeza de este precepto legal.

El artículo 20 del Convenio Multilateral Iberoamericano ${ }^{2}$ (en adelante CMI), por tratarse de un artículo de trámite o procedimiento, insertado en el Título III sobre "mecanismos de cooperación administrativa", puede pasar inadvertido en un primer estudio de la materia, a diferencia de aquellas reglas para la determinación de la legislación aplicable (ámbito personal, campo material, igualdad de trato, totalización de periodos, derechos adquiridos, revalorización de pensiones, relaciones del Convenio con otros instrumentos de coordinación de Seguridad Social, etc.) o de las disposiciones específicas para las distintas categorías de prestaciones (régimen de prestaciones, pensiones de invalidez, vejez y supervivencia, transferencia de fondos, etc.).

Lo cierto y verdad es que sin intercambio de información no se podría dar cumplimiento a los principios inspiradores del Convenio, resumidos en la urgencia de contar con un instrumento de coordinación de las distintas legislaciones nacionales en materia de pensiones, que garantice los derechos de todos los trabajadores migrantes y sus familias, protegidos bajo los esquemas de Seguridad Social de los diferentes Estados Iberoamericanos, y que les permita disfrutar de los beneficios generados con su trabajo en los países receptores.

\section{EL INTERCAMBIO DE INFORMACIÓN}

Tradicionalmente, dentro de los Convenios Bilaterales, se observa un triple contenido, de acuerdo a la naturaleza jurídica y alcance normativo o no de las cláusulas en ellos contenidos.

El articulado es susceptible de ordenarse en tres categorías, en función de si atienden al contenido necesario $^{3}$, al contenido normativo ${ }^{4}$ o al contenido obligacional ${ }^{5}$.

\footnotetext{
${ }^{1}$ www.documentalistaenredado.net/834/la-informacion-en-si-no-es-poder/

${ }^{2}$ El Convenio Multilateral Iberoamericano de Seguridad Social, Boletín Oficial del Estado, n ${ }^{\circ}$ 7, de 8 de enero de 2011, pp.1645-1665, de forma contigua al texto del Acuerdo de Aplicación del Convenio Multilateral Iberoamericano de Seguridad Social, pp. 1630-1643.

${ }^{3}$ Las cláusulas identificativas de las altas partes contratantes, las autoridades administrativas competentes, las entidades e instituciones gestoras encargadas del cumplimiento de las prestaciones comprometidas, la determinación del ámbito personal y sus excepciones, la determinación del ámbito temporal (la entrada en vigor del convenio o la duración del convenio, el ámbito territorial donde será aplicado, y el ámbito objetivo.

${ }^{4}$ Las contingencias protegidas, los principios que rigen el contenido normativo (principio de igualdad de trato, conservación de los derechos adquiridos, mantenimiento de los derechos en curso de adquisición)

${ }^{5}$ Las obligaciones relativas a la ayuda administrativa mutua, los compromisos asumidos en orden a concertar con posterioridad acuerdos administrativos para la aplicación del convenio, las referencias expresas a las obligaciones contraídas derivadas de la ratificación del convenio, y los medios para la solución de conflictos de aplicación.
}

e-Revista Internacional de la Protección Social, ISNN 2445-3269. 2016, Vol. I, No 2

http://dx.doi.org/10.12795/e-RIPS.2016.i02.21

Página 241 
El intercambio de información se ubica dentro la categoría de contenido obligacional, al producir efectos obligacionales al igual que cualquier otro contrato, aunque aquí modalizado por ser un pacto entre Estados, es decir, se trata de una parcela del contenido que no tiene, pues, alcance para los nacionales pertenecientes a los respectivos Estados, sino que sólo es exigible entre y por las partes firmantes respectivas $^{6}$.

El contenido obligacional de los convenios bilaterales está integrada por las cláusulas articuladas que, desde el punto de vista del Derecho internacional público, regulan la relación jurídica que se origina, a partir de y por el instrumento bilateral, entre los Estados firmantes $\mathrm{y}$, de forma derivada, entre las autoridades administrativas competentes, por un lado, y entre las entidades gestoras respectivamente competentes de la Seguridad Social, por otro ${ }^{7}$.

La obligación de ayuda administrativa mutua, de uso consolidado en Derecho internacional público ${ }^{8}$, resulta el máximo exponente del principio de colaboración administrativa. Esta colaboración administrativa se manifiesta con una serie de pequeñas actuaciones, que como se detallará en el apartado siguiente sobre la comparativa entre Convenios Bilaterales, pueden darse o no juntas o por separado.

Estas obligaciones de información recíproca pueden consistir en:

- El sometimiento a reconocimientos médicos necesarios para el cumplimiento de las disposiciones legales de un Estado contratante, respecto de las personas que se encuentran en el territorio del otro Estado.

- El idioma de comunicación por parte de las autoridades como entidades competentes (en este caso español y portugués), hasta el punto que se puede utilizar la propia lengua oficial y la contraparte no se puede negar a admitir cualquier tipo de documentación (instancias, recursos, etc.) por el hecho de estar redactados en la lengua oficial del otro Estado.

- El lugar de presentación de documentos y escritos tanto administrativos como judiciales.

- El intercambio de información tanto respecto de las medidas adoptadas para la aplicación del convenio como las modificaciones legislativas o normas complementarias que pudieran repercutir en la aplicación del convenio.

- La bonificación o exención de tasas e impuestos.

- El compromiso de coordinación financiera, en atención a pagos, transferencias monetarias, errores de pagos, liberación de obligaciones.

Por tanto, se puede afirmar que el Convenio Multilateral es un instrumento internacional ideado para facilitar la libre circulación de trabajadores en el seno de la Comunidad Iberoamericana, si bien no tiene por objeto ni armonizar ni unificar los

\footnotetext{
${ }^{6}$ Pérez Pérez, M.;“Convenios Bilaterales de Seguridad Social Ratificados por España”. Relaciones Laborales, tomo 1/1985, p. 189.

${ }^{7}$ Pérez Pérez, M.;“Convenios Bilaterales...Op.cit. pág. 189.

${ }^{8}$ Montoya Melgar, A.; "El Derecho Internacional de la Seguridad Social”. Revista de Política Social $n^{\circ}$ 61/1964, p. 412. Además, señalaba el autor como un sector de la doctrina francesa había inducido que las relaciones internacionales de Seguridad Social formarían parte de un pretendido "Derecho administrativo internacional" o, incluso, de un "Derecho de la coordinación administrativa internacional", al respecto, Simons:"La Conception du Droit International Privé d'aprés la Doctrine et la Prattique en Allemagne". Recueil des Cours, 1926, V, págs. 437 y ss.
} 
sistemas de Seguridad de los Estados signatarios, sino que tiene una finalidad mucho más restringida: coordinar únicamente las prestaciones contributivas de Seguridad Social de los Estados Parte ${ }^{9}$.

El CMI es considerado ejemplo y auténtico legatario de las normas europeas de coordinación. En este sentido, el art. 84 del antiguo Reglamento 1408/71 (nuevo Reglamento 883/2004) contiene disposiciones que tratan de superar las posibles barreras administrativas de gestión, liquidación o pago de las prestaciones, facilitando la validez de los reconocimientos médicos realizados al efecto en cualquier Estado, del pago de las prestaciones en el país de residencia por parte de dicho Estado aunque no sea el obligado, de la recaudación de cotizaciones en el territorio de un Estado que no sea el que las ingresa, de la validez y facilidad de la presentación y curso de solicitudes y documentos en Estados que no sea el encargado de tramitarlas ${ }^{10}$.

De igual manera, la aplicación de estas disposiciones administrativas en el Convenio Multilateral, están supeditadas a la celebración de Acuerdos administrativos, donde se designarán los respectivos Organismos de Enlace, se acordará la intercomunicación de las medidas adoptadas en el plano interno para la aplicación del Convenio y se notificarán todas las disposiciones legales y reglamentarias modificativas del mismo, y prestarse los Estados la más amplia colaboración administrativa, en concreto $^{11}$ :

- Las diferencias que puedan surgir en la interpretación y aplicación del Convenio se resolverán de común acuerdo entre las Autoridades de los Estados Parte. Las diferencias insalvables serán resultas de conformidad a una Comisión arbitral ${ }^{12}$ (art. $28 \mathrm{CMI}$ ).

- Las solicitudes y documentos presentados ante las Autoridades o Instituciones Competentes de cualquier Estado Parte donde el interesado acredite períodos de seguro, cotización o empleo o tenga su residencia, surtirán efecto como si se hubieran presentado ante las Autoridades o Instituciones Competentes correspondientes del otro Estado Parte, siempre que el interesado lo solicite expresamente o, si de la documentación presentada se deduce la existencia de períodos de seguro, cotización o empleo en este último Estado Parte (art. 21 CMI).

- Cuando la Institución Competente de un Estado Parte haya abonado prestaciones y se proponga actuar contra la persona que las haya percibido indebidamente, la Institución Competente del lugar de residencia de esta persona, o la institución designada al efecto por la Autoridad Competente del Estado Parte en cuyo

\footnotetext{
${ }^{9}$ Sánchez-Rodas Navarro, C.; “Aproximación a la Coordinación de Regímenes de Seguridad Social en el Reglamento 883/2004 y en el Convenio Multilateral Iberoamericano de Seguridad Social, Revista Internacional de la Protección Social”, vol. 1, n¹/2016, p. 4.

${ }^{10}$ Sánchez Carrión, J.L.; “Los Convenios Bilaterales de Seguridad Social suscritos por España y su conexión con el Derecho Comunitario”. Revista del Ministerio de Trabajo y Asuntos Sociales no 47/2003, p. 44.

${ }^{11}$ Sánchez Carrión, J.L.;"Los Convenios Bilaterales...Op.cit. p.45.

${ }^{12}$ Dentro de los Convenios bilaterales firmados por España aparecen dos modalidades de solución de conflictos: además de la Comisión arbitral (los Convenios con EEUU, Uruguay, Marruecos, Chile, Filipinas, Méjico, Perú, Andorra, Túnez, Ecuador, Paraguay, y Acuerdo administrativo con Australia), la vía diplomática (los Convenios con Rusia, Ucrania, Argentina, Brasil, Australia, Canadá, Venezuela).
}

e-Revista Internacional de la Protección Social, ISNN 2445-3269. 2016, Vol. I, No 2 
territorio resida dicha persona, ayudará, en la medida que lo permita su ordenamiento jurídico, con sus buenos oficios a la primera institución (arts. 26.1 y 27.1 Acuerdo Aplicación CMI).

- Los reconocimientos médicos serán financiados, por la Institución Competente del Estado Parte que solicitó los exámenes y/o, si así lo determina la legislación interna, por el solicitante o beneficiario, para lo cual, la Institución Competente del Estado Parte que solicitó la evaluación médica podrá deducir el costo que le corresponde asumir al solicitante o beneficiario, de las prestaciones económicas devengadas o del saldo de su cuenta de capitalización individual, en su caso (art. $19 \mathrm{CMI})$.

- Los Organismos de Enlace de los diferentes Estados Parte intercambiarán las estadísticas referentes a los abonos de prestaciones efectuados a los beneficiarios de un Estado Parte que residan en otro Estado Parte. Estas estadísticas contendrán, como mínimo, el número de beneficiarios, tipo de prestaciones y la cuantía total de las prestaciones abonadas durante cada año calendario o civil (art. 27.2 Acuerdo Aplicación CMI).

- Las prestaciones reconocidas por aplicación de este Convenio a beneficiarios que residan en un tercer país, se harán efectivas en las mismas condiciones y con igual extensión que a los propios nacionales que residan en ese tercer país (art. 6.2 CMI)

Tal es la relación entre el Reglamento de coordinación europeo y el CMI, que hasta el Secretario General de la Organización Iberoamericana de Seguridad Social (OISS) lo destacó en la presentación del CMI al Comité Económico y Social europeo, reseñando además en su intervención la necesidad ibérica de contar con un instrumento, en parte similar al europeo, dado el alto flujo migratorio en la región, pues a pesar de las afinidades históricas, culturales e idiomáticas ${ }^{13}$, existe una carencia de base jurídicopolítica como la existente en la UE o MERCOSUR, situación que ha requerido de una gran voluntariedad y unanimidad política en la coordinación multilateral de los sistemas de pensiones, tan diferentes de un país a otro ${ }^{14}$.

Por tanto, se destaca la coordinación como la nota común entre ambos instrumentos ${ }^{15}$, aunque ni en el ámbito del Derecho de la Unión Europea ni en el articulado del Convenio Multilateral cuenten con una definición jurídica precisa, aunque de la jurisprudencia del Tribunal de Justicia de la UE se infiere que la coordinación ${ }^{16}$ :

- No implica unificación ni armonización de sistemas de Seguridad Social.

- No conlleva la derogación, reforma, o modificación de los sistemas nacionales de Seguridad Social coordinados que subsisten con todas sus peculiaridades.

- No veda las competencias soberanas de los Estados para legislar en el ámbito de la Seguridad Social.

\footnotetext{
${ }^{13}$ www.oiss.org/El-Secretario-General-de-la-OISS,6125.html

${ }^{14}$ Jiménez Fernández, A.; "Convenio Multilateral Iberoamericano de Seguridad Social” en: VV.AA.:"El Futuro de la Protección Social”. Laborum. Murcia. 2010; p. 375.

${ }^{15}$ Sánchez-Rodas Navarro, C.;"El Convenio Multilateral Iberoamericano de Seguridad Social”. Revista General de Derecho del Trabajo y la Seguridad Social n²6/2011, p. 215
}

${ }^{16}$ Sánchez-Rodas Navarro, C.;“Aproximación...op.cit. pp. 5-6.

e-Revista Internacional de la Protección Social, ISNN 2445-3269. 2016, Vol. I, No 2 
- No es un fin en sí mismo, sino un instrumento para facilitar, en última instancia, la libre circulación de trabajadores en el seno de la Comunidad Iberoamericana (por lo que al Convenio Multilateral se refiere) y en el ámbito de la Unión Europea por lo que respecta al Reglamento 883/2004.

- Permite salvaguardar los derechos adquiridos y en curso de adquisición de los migrantes en el ámbito de la Seguridad Social, evitando que los trabajadores migrantes vean mermados sus derechos y/o expectativas de derecho en materia de Seguridad Social.

- Tanto el Reglamento 883/2004 como el Convenio Multilateral garantizan a los sujetos incluidos dentro de sus respectivos ámbitos de aplicación un trato igual al dispensado a los trabajadores nacionales.

El intercambio de información previsto por el art. 20 CMI se caracteriza por ser un contenido múltiple y sentido bidireccional. El primer punto de este artículo obliga a las Autoridades Competentes de los Estados Parte la comunicación de la información relacionada no sólo con las medidas adoptadas para la aplicación del presente Convenio, sino también de las modificaciones de sus respectivas legislaciones que pudieran afectar a la aplicación del Convenio.

Para alcanzar tal objetivo, las Autoridades e Instituciones Competentes de los Estados Parte deberán prestar sus buenos oficios y actuaciones como si se tratase de aplicar sus propias legislaciones, facilitando con carácter general, asistencia gratuita.

Además, las instituciones competentes responderán a todas las peticiones en un plazo razonable informando a las personas interesadas sobre cualquier extremo necesario para hacer valer los derechos que reconocidos por el CMI.

De otro lado, las personas interesadas quedan obligadas a informar cuanto antes a las instituciones del Estado Parte competente y del Estado Parte de residencia, de cualquier cambio en su situación personal o familiar que pudieran tener incidencia en el derecho a las prestaciones.

En cuanto a las limitaciones al intercambio de información se pueden señalar de dos tipos: directas e indirectas.

Las primeras están contenidas en el propio convenio, la cláusula del art. 5 CMI sobre protección de datos personales, estableciendo que las comunicaciones con datos personales a otra institución extranjera se regirán por la legislación en materia de protección de datos de carácter personal del Estado emisor, mientras que será de aplicación la legislación en materia de protección de datos del Estado receptor de dichas comunicaciones por lo que respecta a la protección, registro, modificación o destrucción de dichos datos.

Igualmente, de conformidad con el art 3.3 del Convenio Multilateral, existe una limitación al afirmar que éste no será de aplicación a las prestaciones económicas reseñadas en el Anexo II, y bajo ninguna circunstancia podrá incluir alguna de las ramas de seguridad social señaladas en el apartado 1 de este artículo. En relación al Anexo II España ha notificado el auxilio por defunción.

En cuanto a las segundas, sobre las limitaciones indirectas cabría señalar aquella información que no se tramitará por no ser materia objeto de acuerdo del propio convenio. En este sentido, respecto al ámbito de aplicación personal, de acuerdo a la previsión del art. 3.2 CMI, España ha notificado en el Anexo I la exclusión de los 
regímenes especiales de los Funcionarios Civiles del Estado, de las Fuerzas Armadas y de la Administración de Justicia.

Igualmente, las prestaciones no contributivas no están contempladas dentro del Convenio Multilateral, y en tales supuestos se exigirá la residencia en territorio nacional para percibir los complementos por mínimos ya que éstos tienen naturaleza no contributiva.

\section{MEDIDAS SIMILARES REGULADAS EN OTROS CONVENIOS BILATERALES}

Se puede extraer otra idea acerca de la extensión del artículo 20 CMI respecto de los Convenios Bilaterales de cada uno de aquellos Estados firmantes que hayan ratificado el Convenio y suscrito el Acuerdo, e incluso, entre los propios Convenios bilaterales de estos Estados entre sí.

En primer lugar, el Estado español cuenta con Convenios Bilaterales ${ }^{17}$ firmados con cada uno de los socios mencionados que han satisfecho ambos requisitos, a excepción de Bolivia y El Salvador. Para el resto, la tónica respecto al intercambio de información, es la previsión de un artículo rubricado «ayuda administrativa entre instituciones» como recogen los Convenios con Brasil (art. 31), Chile (art. 36), Ecuador (art. 26), Uruguay (art. 23) y Paraguay (art. 27). No obstante, ninguno de ellos es homologable al contenido del art. $20 \mathrm{CMI}$.

En general, lo que predomina en cada uno de estos artículos es el intercambio de información, pero derivada del establecimiento de mecanismos de control, tales como reconocimientos médicos, comprobaciones de hechos y actos de los que puedan derivarse la adquisición, modificación, suspensión, extinción o mantenimiento del derecho a prestaciones por las otras instituciones.

Asimismo, aparecen también previsiones para el reintegro de dichos gastos por la Institución Competente que solicitase el reconocimiento o la comprobación. Igualmente, existen previsiones para la retención de prestaciones, cuando una Institución competente comprobase que ha pagado al beneficiario de prestaciones una cantidad superior a la debida, solicitándolo a la Institución competente de la otra Parte.

Pero esta situación también se produce respecto a convenios firmados con otros países, por ejemplo, el convenio con Argentina (art. 21 colaboración administrativa entre instituciones), con Ucrania (art. 19 colaboración administrativa entre administraciones competentes) o con Venezuela (art. 28).

En cambio, el artículo 24 del Convenio hispano-japonés, sí prevé una colaboración administrativa más en línea con el artículo $20 \mathrm{CMI}$, esto es, comunicarse mutuamente tan pronto como sea posible, toda la información sobre las modificaciones de su

\footnotetext{
${ }^{17}$ Cfr. entre los Convenios de carácter multilateral sobre Seguridad Social suscritos por España: El Convenio entre los Gobiernos de España, República Federal de Alemania y República francesa relativo a la extensión de ciertas disposiciones de Seguridad Social (BOE de 27 de enero de 1979). El Convenio entre los Gobiernos de España, República francesa y República portuguesa, relativo a la ampliación del beneficio de determinadas disposiciones de los Convenios de Seguridad Social, concertados entre dos de dichos Estados, a los nacionales de tercer Estado (BOE 8 de mayo de 1984). El Convenio Europeo de Seguridad Social (BOE de 12 de noviembre de 1986). El Convenio sobre Relaciones Consulares (BOE de 24 de enero de 1968). El Convenio sobre relaciones Consulares (BOE de 6 de marzo de 1970).
}

e-Revista Internacional de la Protección Social, ISNN 2445-3269. 2016, Vol. I, No 2 
legislación y cualquier otro cambio que afecte a la aplicación de este Convenio, y dentro del campo de sus respectivas competencias, prestándose asistencia mutua para la aplicación de este Convenio las Autoridades e Instituciones competentes de ambas Partes con carácter gratuito.

En segundo lugar, desde la óptica del vecino ordenamiento de Portugal, destacan el art. 29 de su Convenio con Venezuela ${ }^{18}$ sobre comunicación directa, las referencias al intercambio de información y asistencia mutua, en el art. 27 del Convenio Bilateral con Australia $^{19}$, donde es llamativo el hecho de la posibilidad de intercambios administrativos en una tercera lengua, francés, y las previsiones de cooperación de las autoridades e instituciones competentes del art. 33 del Convenio con Marruecos ${ }^{20}$, o art. 38 del Convenio con Túnez ${ }^{21}$, o el art. 27 del Convenio con Moldavia ${ }^{22}$.

En tercer lugar, desde la vertiente latinoamericana, con carácter general, se puede señalar el art. 10 de cooperación administrativa, del Acuerdo Multilateral de Seguridad Social del Mercado Común del Sur ${ }^{23}$ (MERCOSUR) que dispone el examen pericial entre las Administraciones de Argentina, Brasil, Paraguay y Uruguay, realizados por la Entidad Gestora de un Estado Parte y a cuenta de la Entidad Gestora del Estado solicitante.

Con carácter más específico, se encuentran entre otros:

Los Convenios firmados por la República de Chile ${ }^{24}$ con: Colombia (art. 24 asistencia recíproca y colaboración administrativa), Finlandia (art. 16 acuerdo administrativo e intercambio de información), Dinamarca (art. 20), Alemania (art. 15. asistencia administrativa y judicial), Luxemburgo (asistencia mutua en materia administrativa), República Checa, Reino Unido (art.10), Quebec (art. 16 arreglo administrativo), Portugal (art. 17 asistencia mutua) o Noruega (Art. 17 asistencia recíproca).

Los Convenios firmados por Paraguay con: Países Bajos ${ }^{25}$ (art. 6.6. verificación de solicitudes y pagos), o con el vecino Chile ${ }^{26}$, cuyo art. 25 de asistencia recíproca está plagado de especifidades.

\footnotetext{
${ }^{18}$ www.seg-social.pt/documents/10152/47921/D_27_92/63b081ee-f794-4763-9484-9a8169532f51

"Para a devida aplicação e cumprimento da presente Convenção, as autoridades competentes, organismos de ligação e instituições das duas Partes comunicarão directamente entre si”.

${ }^{19}$ www.seg-social.pt/documents/10152/36210/D_11_2002/66cdc6d2-0fe0-41a2-baa2-15e820c77b64

"As autoridades e as instituições das duas Partes Contratantes correspondemse nas respectivas línguas oficiais. Todavia, as autoridades e instituições de uma Parte Contratante não podem recusar pedidos ou outros docu- mentos que lhe sejam dirigidos pelo facto de serem redigidos em francés".

${ }^{20}$ www.seg-social.pt/documents/10152/47928/D_27_99/60696bc4-d961-4db7-b681-a2b41aa51c0e

${ }^{21}$ www.seg-social.pt/documents/10152/38507/RAR_29_2009/e7efaf64-94dd-43f9-ac1a-341a3ea0f0cc

${ }^{22}$ www.seg-social.pt/documents/10152/38449/RAR_108_2010/eb358a04-703a-4b2d-a7cf-422f217767c0

${ }^{23}$ www.bps.gub.uy/bps/file/3855/23/mercosur_acuerdo_y_reglamento.pdf

${ }^{24}$ www.ips.gob.cl/empleador-18857/convenios-internacionales/76-trabajador/articulos-83312/313convenios-internacionales-de-seguridad-social-vigentes-
}

25 www.mtess.gov.py/index.php/dgss/marco-legal/convenios/ley-3160-convenio-internacional-bilateralentre-paraguay-y-e

e-Revista Internacional de la Protección Social, ISNN 2445-3269. 2016, Vol. I, No 2 
Este artículo prevé que las Autoridades, Organismos e Instituciones Competentes de ambas Partes podrán comunicarse directamente entre sí y con las personas interesadas incluso a través de canales diplomáticos y consulares, pudiendo representar y asesorar sobre procedimientos administrativos y trámites necesarios, con carácter gratuito y bajo instancia del interesado, a sus propios nacionales.

Además, tratándose del sistema de capitalización individual chileno, no se aceptará tal representación para los efectos de la selección de la modalidad de pensión por al cual opte el afiliado.

Los Convenios firmados por Uruguay con: Bélgica ${ }^{27}$ (art. 23 cooperación administrativa) especifica que las Autoridades Competentes pueden convenir el reembolso de determinados gastos; con Bolivia $^{28}$ (arts. 20 y 22) donde se prevé la modificación de común acuerdo y cuando sea necesario, de los procesos administrativos establecidos en el Acuerdo, a fin de lograr una mejor aplicación de éste, debiendo comunicar a la autoridad competente respectiva; con Quebec ${ }^{29}$ (art. 26 comunicaciones) prevé que ambas Partes Contratantes puedan comunicarse entre sí en su idioma oficial; con Italia $^{30}$ (art. 35); con los Países Bajos ${ }^{31}$ (art. 19 ayuda administrativa) donde se destaca que los Organismos de Enlace de ambas Partes intercambiarán los datos estadísticos relativos a los pagos de pensiones concedidos a los beneficiarios de una Parte Contratante que residan en el territorio de la otra Parte Contratante, los cuales, contendrán el número de beneficiarios y el importe total de los pagos de pensiones satisfechos por año natural.

Además detalla este Convenio que podrá ser intercambiada entre los Organismos de Enlace de cada Parte Contratante, de forma electrónica o por otro medio de información acordado, garantizando siempre el acceso limitado y la confidencialidad.

\section{CONCUSIONES}

En resumen, el intercambio de información, subsumido dentro de la colaboración administrativa, atiende a la presencia polivalente del principio de reciprocidad.

Aunque todo proceso burocrático es siempre susceptible de mejora, resulta plausible el esfuerzo realizado en los últimos tiempos para dar respuesta a una exigencia del mundo del trabajo iberoamericano: la implicación de todas las Administraciones de Seguridad Social de los Estados Parte firmantes del Convenio y del Acuerdo de Aplicación, eliminando de esta manera los obstáculos administrativos a la movilidad laboral en mercados de trabajo cada vez más globalizados.

\footnotetext{
26 www.mtess.gov.py/index.php/dgss/marco-legal/convenios/ley-4634-convenio-internacional-bilateralentre-paraguay-y-c

${ }^{27}$ www.bps.gub.uy/bps/file/3855/23/uruguay_-_belgica.pdf

${ }^{28}$ www.bps.gub.uy/bps/file/3855/23/bolivia.pdf

${ }^{29}$ www.bps.gub.uy/bps/file/3855/23/quebec.pdf

${ }^{30}$ www.bps.gub.uy/bps/file/3855/23/italia_convenio_y_acuerdo.pdf

${ }^{31}$ http://www.bps.gub.uy/bps/file/3855/23/holanda_paises_bajos_convenio_y_acuerdo.pdf
}

e-Revista Internacional de la Protección Social, ISNN 2445-3269. 2016, Vol. I, No 2

http://dx.doi.org/10.12795/e-RIPS.2016.i02.21 
Dentro de la Unión Europea, España se presenta a la cabeza en la firma de estos convenios. La mayoría de los Convenios bilaterales firmados por España lo han sido respecto a Estados iberoamericanos.

De este modo, se da cumplimiento a la Comunicación publicada recientemente por la Comisión Europea, cuyo objetivo principal es fomentar una mayor cooperación entre los Estados miembros en el ámbito de la coordinación con terceros países en materia de Seguridad Social ${ }^{32}$.

Por último, si a través de las líneas precedentes, se ha podido apreciar la magnitud del volumen de información manejado por las partes implicadas, piénsese entonces, en la magnitud que supondría la hipotética suma futura de Convenios entre el continente sudamericano y europeo, -estructuralmente muy similares a excepción del campo objetivo obligatorio de aplicación del CMI más reducido que los Reglamentos de coordinación- dando lugar a una mayor cooperación interregional euroiberoamericana ${ }^{33}$.

\footnotetext{
${ }^{32}$ COM (2012) 153 final, de 30 marzo 2012: La Dimensión Exterior de la Coordinación en Materia de Seguridad Social de la UE.

${ }^{33}$ García de Cortázar Nebreda, C.;"La Dimensión Externa de las Normas de Coordinación Europea de Seguridad Social. El Reglamento 883/2004 y el Convenio Multilateral Iberoamericano de Seguridad Social". Revista del Ministerio de Trabajo e Inmigración, no extra 1/2010, p. 275.
} 